\title{
Pengelolaan Terbitan Berseri Di Perpustakaan Sekolah Man 2 \\ Palembang
}

\section{Rendy Andrean, Nabila Ainun Nazifah, Mutiara Aisya dan Ike Noviati}

\section{Abstract}

The purpose of this research is: (a) to describe the management of serial publication in MAN 2 Palembang library, (b) to describe the service of serial publication in libraries MAN 2 Palembang, (c) to describe SNI serialized in MAN 2 Palembang library. The method used in this study using descriptive approach through observation and interview conducted directly in the library MAN 2 Palembang. The technique used in collecting data is through observation and direct interview with Mrs. Dra. Lisnawati as head of MAN 2 Palembang library.

Keywords: serial publications, school libraries, periodical publications

\section{Pendahuluan}

Dalam Undang-Undang Republik Indonesia Nomor 43 tahun 2007, tentang perpustakaan, pemustaka adalah pengguna perpustakaan yang terdiri dari perseorangan, kelompok orang, masyarakat atau lembaga yang memanfaatkan fasilitas layanan perpustakaan. Dengan demikian untuk merekalah perpustakaan dibangun dan dikembangkan sesuai dengan tuntutannya. Dengan demikian kepuasan pemustaka perlu secara berkelanjutan diupayakan dengan tujuan agar mereka terus memanfaatkan perpustakaan.

Perpustakaan merupakan organisasi publik yang memiliki peran strategis dalam upaya mencerdaskan kehidupan bangsa. Perkembangan perpustakaan mencerminkan kehidupan bangsa, kebutuhan sosial, kultural, dan pendidikan suatu masyarakat, sehingga perkembangan perpustakaan tidak terlepas dari perkembangan masyarakat itu sendiri. Hal tersebut berarti bahwa perkembangan perpustakaan akan dipengaruhi oleh 
perkembangan kebutuhan dan keinginan dari pemustakanya, sehingga perpustakaan harus mengupayakan pemenuhan terhadap keinginan dan kebutuhan pemustaka tersebu sehingga pemustaka merasa puas dengan pelayanan yang ada di perpustakaan.

Untuk menciptakan kepuasan pemustaka, perpustakaan harus dapat memenuhi harapan dari pemustaka tersebut, salah satunya adalah melengkapi kebutuhan koleksinya. Koleksi yang ada diperpustakaan dapat berupa sebagai berikut:

a. Buku Fiksi

b. Buku Non Fiksi terdiri dari:
a. Buku karya umum
b. Filsafat dan Ilmu Jiwa
c. Agama
d. Pengetahuan Sosial
e. Bahasa
f. Ilmu Pengetahuan Alam
g. Ilmu terapan
h. Kesenian dan Olahraga
i. Kesusastraan
j. Sejarah dan Geografi

c. Buku referensi
a. Kamus
b. Ensiklopedi
c. Direktori
d. Buku tahunan
e. Indeks
f. Almanak
g. Atlas
h. Bibliografi
i. Sumber bibliografi
j. Statistik
k. Buku pegangan

d. Bahan Audiovisual
a. Kaset
b. Piringan hitam
c. Film
d. Mikrofilm
e. Slide
f. Vidio
g. Kaset
h. Disc

e. Terbitan berkala

a. Surat kabar 

b. Majalah
c. Buletin
d. Jurnal

Dari beraneka macam koleksi perpustakaan yang harus dilengkapi demi kepuasan pemustaka, terdapat koleksi terbitan berkala atau terbitan berseri. Terbitan ini sangatlah istimewa karena terbitan ini merupakan salah satu terbitan yang informasinya sangat ter update dan masih fresh sekali serta informasi yang ada di koleksi terbitan berseri ini merupakan salah satu sumber informasi primer. Terbitan berseri khususnya di bagian majalah dan jurnal ilmiah mempunyai peran penting yaitu memberikan ruang untuk menampung ide, gagasan, dan pengalaman seseorang. Pemikiran tersebut dituangkan didalam bentuk karangan ataupun ulasan yang dimuat dalam lembaran terbitan berseri. Selain itu terbitan berseri juga sebagai media untuk menyampaikan gagasan dan penemuan baru dalam bidang tertentu. Seperti halnya Lasa HS menyebutkan bahwa Terbitan berseri memiliki peran penting yaitu:

- Memberikan ruang untuk menampung ide/gagasan/ pengalaman beberapa orang.

- Memberikan gambaran/potret peristiwa, kejadian, situasi yang terjadi dalam berbagai bidang.

- Berfungsi sebagai media komunikasi dua arah

Berdasarkan prinsip penting yang disampaikan oleh Lasa HS, Terlihat jelas bahwa terbitan berseri sangatlah penting sesuai dengan kebutuhan pemustaka dalam kegiatan penelitian guna pengembangan ilmu pengetahuan dan teknologi. The ALA Glossary of Library and Information Science defines the Serial as " $a$ publication issued in successive parts, usually at regular intervals, and, as a rule, intended to be continued indefinitely." 1 Mendefinisikan terbitan berseri sebagai publikasi yang diterbitkan

\footnotetext{
1 Priya TK dan Abdul Majeed, "studies on serials management in Libraries: a review", International Journal of Digital Library Services Vol. 5, Juli - September 2015, hal. 103
} 
di bagian yang berurutan, biasanya secara berkala, dan, sebagai suatu peraturan, dimaksudkan untuk dilanjutkan tanpa batas.

Dengan demikian melihat pentingnya koleksi terbitan berseri maka perpustakaan harus memiliki koleksi-koleksi yang dapat menunjang proses belajar mengajar didalam suatu lembaga. Berdasarkan observasi di perpustakaan MAN 2 Palembang, terlihat bahwa koleksi-koleksi yang ada didalam perpustakaan belumlah lengkap. Oleh karena itu kami ingin mendalami lebih lanjut mengenai koleksi yang ada di perpustakaan MAN 2 Palembang, apakah koleksi tersebut sudah menunjang proses belajar mengajar ataukah belum.

\section{Rumusan Masalah}

1. Bagaimana pengelolaan terbitan berseri di perpustakaan MAN 2 Palembang ?

2. Bagaimana Pelayanan Terbitan Berseri yang disediakan di MAN 2 Palembang?

3. Apakah koleksi Terbitan Berseri di MAN 2 Palembang sudah memenuhi standar SNI-7329:2009 Tentang Standar Nasional Perpustakaan Sekolah?

\section{Metode Penelitian}

Metode yang digunakan didalam penulisan ini adalah metode pendekatan deskriptif. Data yang dikumpulkan didapat melalui observasi langsung ke perpustakaanMAN 2 Palembang dan melakukan wawancara langsung dengan Ibu Dra. Lisnawati, seseorang kepala perpustakaan MAN 2 Palembang. Wawancara ini dilakukan berjuan untuk mendapatkan informasi yang benarbenar fakta, tidak hanya melalui pendapat-pendapat orang lain.

\section{Pembahasan}

1. Pengelolaan Terbitan Berseri di MAN 2 Palembang

Pengelolaan merupakan bagian terpenting dalam jalannya sebuah lembaga perpustakaan. Apabila proses pengolaan di perpustakaan berjalan dengan baik tentu saja akan memudahkan 
pemustaka dalam menelusuri informasi dan menunjang untuk akreditasi perpustakaan. Pengelolaan didalam perpustakaan banyak sekali, salah satunya Pengelolaan di koleksi terbitan berseri. terbitan berseri yang masuk keperpustakaan wajib diolah dengan baik agar proses temu kembali informasi nantinya berjalan dengan lancar dan mewujudkan administrasi yang tertib. Proses pengolahan terbitan berseri ini dapat berbeda-beda urutan kegiatan atau alur prosesnya antara perpustakaan satu dengan yang lainnya. hal ini mungkin disebabkan oleh adanya perbedaan budaya kerja, sumber daya manusia dan sarana prasarana dalam proses pengolahan semua tergantung dari kebijakan perpustakaan. Dalam pengelolaan terbitan berseri akan ada beberapa hal yang harus diperhatikan, misalnya :

\section{Penerimaan}

Penerimaan ini merupakan bagian dari proses koleksi terbitan berseri datang keperpustakaan. Diterima dan diolah sesuai dengan prosedur, pada saat koleksi diterima maka harus ada transaksi formal, maksudnya adalah ada kejelasan tentang berapa jumlah koleksi yang masuk, dan judul apa saja yang masuk ke perpustakaan.

2. Proses

Proses yang dimaksud adalah sebuah proses pemberian tanda kepemilikan terhadap koleksi terbitan berseri yang masuk kedalam perpustakaan, pencatatan judul buku dan jumlah eksemplar kedalam buku inventaris, pengklasifikasian koleksi terbitan berseri, penyampulan koleksi agar terlindungi dari berbagai macam hal yang dapat menyebabkan kerusakan dini pada koleksi. Serta, pengimputan bibliografi koleksi terbitan berseri kedalam Opac, agar pemustaka lebih mudah cepat dan tepat dalam mencari informasi yang ada di perpustakaan. 


\section{Selving}

Selving merupakan penempatan koleksi pada rak menurut tatacara tertentu sehingga mudah untuk ditemukan kembali oleh pemakai. Penemuan kembali informasi (retrieval) berarti menemukan informasi yang disimpan diperpustakaan untuk keperluan pemakai. Selving sendiri dilakukan sesuai dengan ilmu pengetahuannya, dapat berupa sesuai dengan nomor kelas (DDC, UDC, dll). Rak yang digunakan untuk koleksi terbitan berseri ini seharusnya memiliki rak tersendiri dan tidak tercampur dengan koleksi perpustakaan lainnya.

Berdasarkan teori yang ada bahwa pengelolaan didalam perpustakaan itu pasti ada yang namanya sistem, sistem yang dimaksud dapat merupakan input-proses-output. Jadi penerimaan koleksi sampai ke selving, merupakan bagian dari sistem yang ada di perpustakaan. Berdasarkan observasi kami di perpustakaan MAN 2 Palembang, terlihat bahwa perpustakaan ini dalam proses pengelolaannya belum sesuai dengan teori yang ada dibuktikan dengan keadaan koleksi terbitan berseri yang ada didalam perpustakaan. Koleksi tersebut hanya berupa majalah, buletin, dan koran dan berdasarkan wawancara, informasi yang didapat adalah koleksi terbitan berseri yang ada di perpustakaan MAN 2 Palembang berasal dari hadiah dari bebagai lembaga dan koleksi tersebut ketika sampai ke perpustakaan hanya diberi cap tanda kepemilikan dan langsung diletakkan dirak yang sudah disediakan dan tidak di cacat di buku inventaris derta tidak diklasifikasi terlebih dahulu. Hal ini disebabkan karena yang bertugas didalam perpustakaan tidak begitu memahami tentang perpustakaan dan pemustakapun jarang untuk membaca koleksi yang termasuk didalam terbitan berseri. Berikut adalah contoh koleksi-koleksi terbitan berseri yang ada diperpustakaan MAN 2 Palembang. 

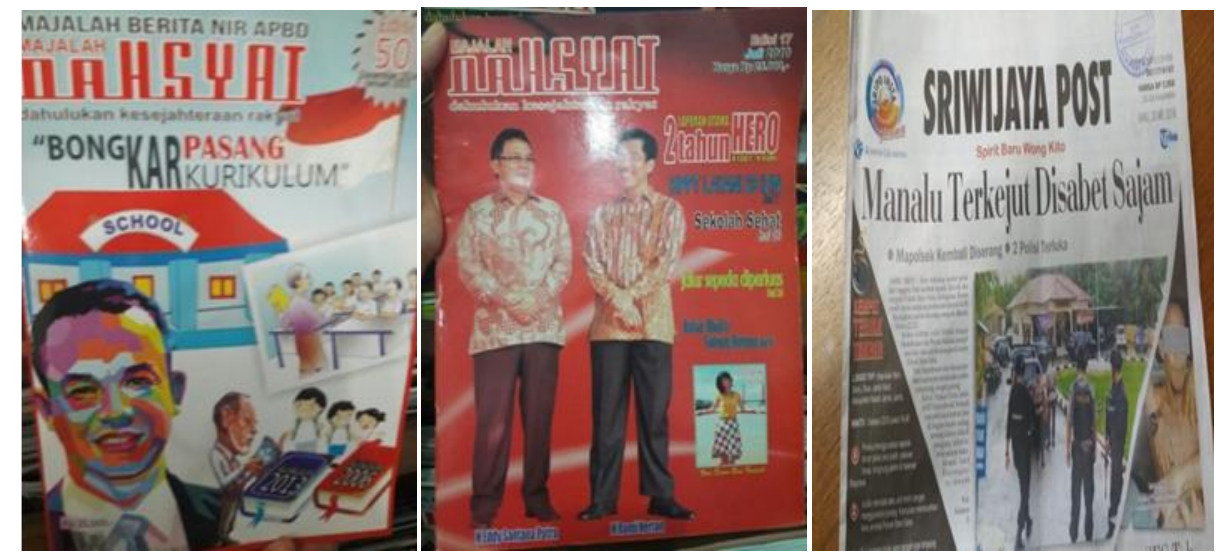

\section{Pelayanan Terbitan Berseri di MAN 2 Palembang}

Layanan merupakan ujung tombak perpustakaan, berhasil tidaknya sebuah perpustakaan dilihat dari kualitas layanan yang diberikan kepada pemustakanya. Layanan perpustakaan menurut Buku Pedoman Perpustakaan Perguruan Tinggi adalah pemberian informasi dan fasilitas kepada pengguna. Melalui layanan perpustakaan, pengguna dapat memperoleh hal berikut:

a. Informasi yang dibutuhkannya secara optimal dari berbagai media

b. Manfaat berbagai alat bantu penelusuran yang tersedia.

Cassel and Hiremath mendefinisikan layanan informasi sebagai proses untuk membantu pengguna perpustakaan untuk mengidentifikasi sumber informasi dalam menanggapi pertanyaan tertentu, minat, tugas, atau masalah. ${ }^{2}$ Dari penjelasan di atas menunjukkan bahwa perpustakaan tidak hanya sekedar mengumpulkan, menyiapkan dan meminjamkan buku dan bahan lainnya tetapi juga mempunyai tugas memberikan layanan informasi yang sifatnya lebih luas dan lebih aktif. Layanan diperpustakaan banyak macamnya, seperti layanan sirkulasi, layanan referensi, layanan pelestarian bahan pustaka dan layanan khusus untuk koleksi terbitan berseri.

2 Pawit M Yusuf, "Pengantar aplikasi teori ilmu sosial komunikasi untuk perpustakaan dan informasi". ( Universitas padjajaran, 2001), hlm. 259 
Salah satu jenis layanan terbitan berseri adanya layanan informasi terseleksi (selective dissemination of information). ${ }^{3}$ Jenis layanan ini merupakan layanan yang memanfaatkan terbitan berseri, yang sangat berguna bagi pemustaka yang selalu ingin mengetahui perkembangan terakhir dari subjek yang diminatinya. Untuk melakukan layanan informasi terseleksi, pustakawan harus meminta data kepada para pengguna yang berminat terhadap layanan ini. Data yang diminta adalah subjek yang diminati oleh pemustaka. Dengan berbekal data subjek yang diminati pemustaka tersebut, pustakawan mencarikan artikel pada berbagai terbitan berseri terbaru yang mungkin memuat artikel yang subjeknya diminati oleh pemustaka. Setelah diperoleh serangkaian judul-judul artikel yang sesuai dengan permintaan pemustaka, maka daftar itu dikirim kepada pemustaka tersebut. Daftar artikel yang dikirim kepada pemustaka akan berbeda dari satu pemustaka ke pemustaka lainnya, bila subjek yang diminati para pemustaka itu memang berbeda.

Untuk memudahkan pengguna dalam memanfaatkan koleksi terbitan berseri, perpustakaan harus menyediakan layanan, sarana dan prasarana khusus untuk koleksi terbitan berseri. Dengan adanya layanan, sarana dan prasarana ini maka koleksi terbitan berseri dapat dimanfaatkan sebagaimana mestinya.

Secara umum, bentuk layanan yang ada dalam sebuah layanan terbitan berseri adalah:

a. Layanan baca

b. Layanan penelusuran/temu kembali informasi layanan informasi terpilih.

c. Layanan informasi cepat

d. Layanan koleksi elektronik dan online digital

e. Layanan bimbingan/bantuan

\footnotetext{
${ }^{3}$ Abdul Rahman Saleh dan Janti G. Sujana, "Pengantar Keperpustakaan", ( Bogor ), hlm. 53
} 
Menurut Rahayuningsih, tujuan layanan terbitan berseri adalah untuk memberikan informasi yang terdapat dalam terbitan berseri kepada pengguna dengan mudah, cepat dan aktual. ${ }^{4}$ Terbitan berseri merupakan koleksi yang masuk ke dalam layanan referensi, American Nasional Standard for Library and Information Statistic yang dikutip oleh RUSA/Reference User Service Association mendefinisikan layanan referensi adalah pemberian informasi yang mengandung penggunaan, rekomendasi, interpretasi, atau instruksi dalam penggunaan satu atau lebih sumber informasi atau pengetahuan oleh salah seorang petugas layanan rujukan atau informasi. Akan tetapi tiap perpustakaan memiliki cara tersendiri bagaimana mengelola atau memberikan pelayanan terhadap terbitan tersebut. Dalam pengelolaan perpustakaan ketika melihat kebijakan perpustakaan maka harus tetap disesuaikan dengan kode etik pustakawan karena kode etik pustakawan berkaitan dengan profesi pustakawan yang sudah memiliki landasan dan tidak bisa melakukan suatu kegiatan yang tidak sesuai dengan kode etik. ${ }^{5}$

Berdasarkan observasi di perpustakaan MAN 2 terlihat bahwa pelayanan terhadap pemustaka sangat kurang sekali, hal ini dilihat berdasarkan perilaku pegawai perpustakaan yang tidak memperhatikan pemustaka yang berkunjung, dan tidak mengarahkan pemustaka untuk mengisi daftar pengunjung. Serta pegawai perpustakaan yang tidak memahami fungsi dan pentingnya koleksi terbitan berseri bahkan pegawai perpustakaan pun tidak mengetahui koleksi mana yang tergolong kedalam koleksi terbitan berseri.

3. Standar Terbitan Berseri di Perpustakaan Sekolah MAN 2 Palembang

\footnotetext{
${ }^{4}$ Clarissa I.R nangka dan Stefi Harilama, Kontribusi Pelayanan Terbitan Berseri untuk Memenuhi Kebutuhan Informasi bagi Mahasiswa di UPT Perpustakaan UNIMA, e-journal "Acta Diurna", Vol. IV, No. 3, ([s.i.] : Universitas Sam Ratulangi, 2015), hlm. 2.

5 Dady P Rachmananta, "Etika Kepustakawanan: suatu pendekatan terhadap kode etik pustakawan Indonesia", (Jakarta: CV. Sagung Seto, 2006), hlm. 61
} 
Terbitan berseri merupakan salah satu koleksi yang harus dimiliki oleh perpustakaan, jenis terbitan berseri banyak sekali misalnya: majalah, surat kabar, tabloid, buku tahunan, seri monograf, prosiding, transcation dll. Untuk standar koleksi terbitan berseri di perpustakaan sekolah ialah sesuai dengan SNI7329:2009 bahwasannya perpustakaan sekolah seharusnya memiliki minimal langganan satu judul majalah dan satu judul surat kabar yang sesuai dengan proses belajar mengajar. Dalam pengadaan koleksi terbitan berseri di perpustakaan sekolah juga seharusnya dilakukan seleksi bahan pustaka, yang memperhatikan evaluasi dan seleksi. Terdapat pihak-pihak yang berwenang melakukan seleksi yaitu, kepala sekolah, wakil kepala sekolah, kepala perpustakaan dan pustakawan.

Prinsip yang di gunakan dalam proses seleksi terbitan berseri adalah: ${ }^{6}$

a. Menggunakan alat seleksi yang tepat

b. Memilih terbitan berseri yang diindeks dalam jurnal

c. Mengikuti informasi yang diberikan oleh new serial title

d. Memperhatikan terbitan berseri yang jarang digunakan oleh pemustaka

e. Mengusahakan melanggan terbitan berseri secara terus menerus

Standardisasi dan standar sudah banyak dikenal untuk bidang industri dan rekayasa. Untuk bidang perpustakaan, dokumentasi, dan informasi ada beberapa standar yang di publikasikan sebagai kendali mutu untuk kegiatan bidang pusdokinfo tersebut. Standar yang berkaitan dengan kegiatan bidang penerbitan di kenal dengan ISO-8-1977 yang digunakan sebagai pedoman untuk kendali mutu terbitan berseri ISO 8-1977 berisi perangkat peraturan yang baku mengenai hal-hal yang berkaitan dengan judul periodikal, terbitan, penomoran majalah,

${ }^{6}$ Aries Hamidah, op. cit. hlm 8 
volume, tanggal, perwajahan, judul, penomoran halaman, penampilan artikel, daftar isi, indeks, dan kasus-kasus khusus.

Dari pokok-pokok yang diatur dalam ISO-8-1977 tersebut dapat di simpulkan bahwa semua aspek tentang terbitan berseri di tata sedemikian rupa sehingga akan dicapai suatu kualitas terbitan berseri bertaraf internasional apabila standar tersebut di terapkan. Koleksi terbitan berseri haruslah memiliki International standard serial number (ISSN) sebagai kode yang dipakai secara internasional untuk terbitan berkala. Satu ISSN berlaku hanya untuk satu terbitan berkala. 7

Berdasarkan teori tersebut terlihat sekali bahwa koleksi terbitan berseri ini sangatlah penting sekali dalam membantu jalannya sebuah aktifitas pembelajaran yang efektif, berdasarkan observasi terlihat bagaimana keadaan perpustakaan MAN 2 Palembang dengan standar yang telah ditetapkan dalam ISO-81975. Koleksi terbitan berseri yang ada diperpuskaan MAN 2 Palembang tidaklah sesuai dengan standar koleksi terbitan berseri perpustakaan sekolah. Perpustakaan MAN 2 Palembang hanya melanggan 1 terbitan surat kabar yang itupun belum sesuai dengan kebutuhan belajar mengajar di sekolahan tersebut. Selain itu perpustakaan tersebut juga tidak melanggan majalah yang sesuai dengan proses belajar mengajar karena perpustakaan tersebut hanya mengandalkan pengadaan koleksi dari hadiah. Terdapat beberapa koleksi majalah dan buletin di perpustakaan tersebut, namun koleksinya sudah terbit terbilang cukup lama. Sehingga berita informasi didalamnya tidak aktual lagi untuk saat ini. Berikut adalah salah satu contoh koleksi terbitan berseri di perpustakaan MAN 2 Palembang:

\footnotetext{
7 Maria ginting, "International standard serial number: Sub bidang katalog induk", jurnal Baca, Vol. 24. No. 1-2 (Maret - juni 1999), hlm. 16
} 

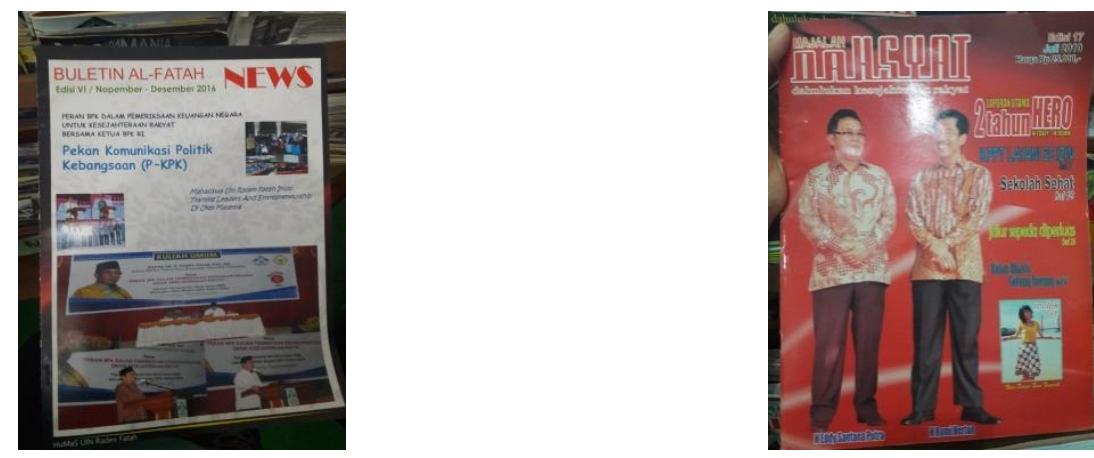

Adapun lembaga yang pernah memberikan hadiah koleksi terbitan berseri kepada perpustakaan MAN 2 Palembang adalah UIN Raden Fatah Palembang, MDP, MA Al-Fatah Palembang dan Dinas Pendidikan Sumatera Selatan. Sebenarnya hal ini sangatlah disayangkan karena peran terbitan berseri dalam proses belajar mengajar di sekolah sangat lah menunjang berjalannya proses pendidikan di lingkungan sekolah.

\section{Penutup}

Kesimpulan dari penelitian ini adalah:

Pengelolaan koleksi terbitan berseri diperpustakaan MAN 2 Palembang belum sesuai dengan teori yang ada karena perpustakaan ini hanya melakukan proses pemberian tanda kepemilikan dan koleksi langsung diletakkan di rak. Padahal seharusnya koleksi yang masuk itu diberi cap tanda kepemilikan, pencatatan inventasris, pengklasifikasian koleksi, penyampulan koleksi, pengimputan kedalam opac dan baru dilakukan selving.

Pelayanan yang ada diperpustakaan MAN 2 Palembang ini sangatlah kurang sekali, karena pegawai perpustakaanya tidak memahami lebih dalam mengenai ilmu perpustakaan.

Perpustakaan MAN 2 Palembang juga belum memenuhi SNI7329:2009 tentang kewajiban untuk memiliki beberapa koleksi terbitan berseri, serta pengelolaan dan pelayanan yang diterapkan belum sesuai dengan SOP/ Standar Operasional Prosedur di perpustakaan sekolah. 


\section{Daftar Pustaka}

Yulia, Yuyu. (2013). Pengelolaan terbitan berseri. Tanggerang selatan: Universitas terbuka.

Hamidah, Aris. Pengelolaan terbitan berseri di UIN Sunan Ampel.

Alam, Umar Falahul. (2016). Shelving dan Diseriontasi Jajaran Koleksi, Jurnal Iqra' Vol.10, No.02. Medan: UIN Sumatera Utara.

Nurmalina. (2015). Layanan referensi di perpustakaan, Jurnal AlKuttab Vol. 2. Palembang: UIN Raden Fatah.

Katz, William A. (2002). Introduction to reference work: reference services and reference process, Vol. II. Eight ed. New york: Mc-Graw-Hill.

Putra, Eka Fauzi. (2017). Kegiatan layanan dalam penelusuran informasi di perpustakaan, Jurnal Iqra' Vol. 11, No. 01. Medan: UIN Sumatera Utara.

Wenni, lilis sudria. (2012). Pengelolaan terbitan berseri, jurnal almaktabah Vol. 11, No. 1. Jakarta: UIN Syarif Hidayatullah.

HS, Lasa. (2017). Manajemen perpustakaan sekolah. Yogyakarta: Pinus book publisher.

Nangka, I.R Clarissa, Harilama, Stefi. (2015). Kontribusi pelayanan terbitan berseri untuk memenuhi kebutuhan informasi bagi mahasiswa di UPT Perpustakaan Unima, e-journal "acta diurna", Vol. IV, No. 3. Universitas Sam Ratulangi.

Yusup, M Pawit. (2001). Pengantar aplikasi teori ilmu sosial komunikasi untuk perpustakaan dan informasi. Universitas Padjadjaran .

Saleh, Abdul Rahman, Sujana, G Janti. (2008). Pengantar keperpustakaan. Bogor.

NS, Sutarno. (2006). Manajemen Perpustakaan suatu pendekatan praktik. Jakarta: CV Sagung Seto.

TK, Priya dan Abdul Majeed. (2015). Studies On Serials Management In Libraries: A Review. International Journal of Digital Library Services Vol. 5

Ginting, Maria. (1999). International standard serial number. Jurnal Baca, Vol. 24, No. 1-2.

Rachmananta, P Dady dan Zen, Zulfikar. (2006). Etika kepustakawanan. Jakarta: CV Sagung Seto. 